\title{
CONFLITOS E TENSÕES NAS DIRETRIZES CURRICULARES DE EDUCAÇÃO FÍSICA: O CAMPO PROFISSIONAL COMO UM ESPAÇO DE LUTAS E DISPUTAS ${ }^{1}$
}

\author{
Samuel de Souza Neto \\ Universidade Estadual Paulista "Júlio de Mesquita Filho", Rio Claro, São Paulo, Brasil \\ Luiz Gustavo Bonatto Rufino \\ Faculdade de Americana, Americana, São Paulo, Brasil \\ Heitor de Andrade Rodrigues \\ Universidade Federal de Goiás, Goiânia, Goiás, Brasil \\ Rubiane Giovane Fonseca \\ Faculdade de Ensino Superior Dom Bosco, Cornélio Procópio, Paraná, Brasil
}

\begin{abstract}
Resumo
Objetivou-se neste trabalho identificar e analisar nas manifestações sobre as DCNs/EF as tensões e os conflitos presentes na profissionalização da Educação Física. Optou-se pelo estudo descritivo-interpretativo, por meio da técnica de videogravação, a partir da seleção de 9 informantes. Da análise emergiram quatro eixos, referentes aos posicionamentos com relação às proposições: reformadores; defensores; debatedores; mediador. Conclui-se que perpassa a discussão das diretrizes a proposição de campo profissional, trazendo à tona o embate de diferentes grupos e perspectivas sobre a profissionalização da Educação Física em disputa. Neste intento, a questão do livre mercado de trabalho une antagonistas históricos, ignorando-se a especificidade da formação de professores.
\end{abstract}

Palavras-chave: Educação Física. Currículo. Prática Profissional. Organizações de Normalização Profissional.

\section{O contexto do estudo, seus cenários, fundamentação e atores}

Este texto trata do debate em torno da Minuta do Projeto de Resolução das Diretrizes Curriculares Nacionais para o curso de graduação em Educação Física (DCNs/EF), Licenciatura, procurando contextualizá-la sob a égide das políticas públicas e das manifestações que envolveram o seu anúncio e materialização preliminar na forma de texto ${ }^{2}$.

No ano de 2015, as Diretrizes Curriculares, ainda em formatação, foram apresentadas pelo relator do processo no encontro realizado na Pontifícia Universidade Católica de Goiás (PUC), na cidade de Goiânia, com alguns direcionamentos, inicialmente tomados como "boa-

\footnotetext{
${ }^{1} \mathrm{O}$ presente trabalho não contou com apoio financeiro de nenhuma natureza para sua realização.

${ }^{2}$ A referida Minuta do Projeto de Resolução está disponível no site do Conselho Nacional de Educação (CNE), sendo possível acessá-la a partir do link: http://portal.mec.gov.br/conselho-nacional-de-educacao/audiencias-econsultas-publicas. As demais manifestações a que nos referimos estão em destaque no quadro 1.
} 
tos". A conjuntura apresentada envolvia as seguintes questões: (a) as Diretrizes Curriculares de Pedagogia que apontava para uma formação única (licenciatura); (b) o conceito de "ato educativo" como norteador da ação profissional para caracterizar a especificidade da Educação Física no campo de atuação em qualquer ambiente de trabalho; (c) os embates do sistema do Conselho Federal de Educação Física, CONFEF com o Conselho Nacional de Educação, CNE e; (d) a perspectiva de uma formação única na Educação Física.

Assim, na forma de um "boato" foram elucidadas nuances de possíveis rumos, na direção de se pensar uma formação única e na perspectiva de se colocar o ato educativo como um polo aglutinador. Nesse sentido, boatos, rumores e memórias fazem parte daqueles momentos da interação social em que os atores sociais confrontam e avaliam os eventos passados, presentes ou iminentes e estabelecem ou reforçam suas identidades sociais (OLIVEIRA, 2015). Porém, o "portador de um boato não o enuncia em qualquer lugar, nem diante de qualquer pessoa, mas apenas quando encontra um quadro propício à interação e à confidência (...). É apenas quando se sente estar entre cúmplices ('cá entre nós') é que se dispõe a revelar seu segredo" (OLIVEIRA, 2015, p.114).

Dando continuidade a este processo, no mês de dezembro de 2015 o documento preconizado e alvo dessa análise circulou pelo país, confirmando o rumor. Em Brasília, na Audiência Pública, após os preâmbulos do CNE, o relator do processo apresentou as justificativas que embasaram a Minuta das Diretrizes Curriculares Nacionais de graduação em Educação Física, Licenciatura. Neste momento, ratificou-se parte do discurso de Goiânia, mas agora materializado na forma de texto, que tomou como base a Resolução CNE/CES 07/2004 (BRASIL, 2004), retirando a terminologia bacharelado para colocar a sua ênfase na licenciatura, assinalando que $40 \%$ do estágio profissional curricular poderá ser feito em outros campos de atuação. $\mathrm{O}$ ato educativo foi reiterado no discurso verbal de apresentação das DCNs/EF, bem como se abriu espaço para que entidades e instituições, que tiveram a sua inscrição reconhecida, ganhassem voz nas manifestações que se seguiram $\left(\mathrm{CBCE}^{3}, \mathrm{KROTON}^{4}\right.$, CONFEF, etc.), apresentando diferentes pontos de vista, favoráveis e contrários a ela, os quais farão parte do nosso objeto de análise.

Em 2016, no Encontro sobre as DCNs/EF, Licenciatura - na Universidade de São Paulo, USP, a repercussão dos discursos anteriores suscitou novos embates e posicionamentos envolvendo entidades e instituições, além de opiniões particulares ou de grupos.

Nesse encontro, reuniram-se representantes das três universidades estaduais paulistas (USP, UNICAMP, UNESP), do CREF4/SP (CONFEF) e do CNE, além de coordenadores de curso de graduação, coordenadores de cursos de pós-graduação e professores universitários de diversas localidades. No âmbito desse processo algumas questões emergiram: o bacharelado em Educação Física não possui uma especificidade própria? Para a formação de professores, formar um profissional que não tem como especificidade a escola não estaria descaracterizando esta formação, bem como o corpo docente? A Educação Física se constituiu numa "nova Pedagogia"?

Neste contexto, o aporte teórico utilizado segue uma inclinação pautada em referenciais sociológicos, apoiando-se no conceito de "campo" fundamentado por Pierre Bourdieu $(1983 ; 1989 ; 1990 ; 1996)$ para a compreensão do "campo profissional", bem como segue uma orientação teórica com base nos estudos da área da Sociologia das Profissões, dos quais Freidson (1998; 2009), Abbott (1988), Bosi (1996), Evetts (2003) podem ser mencionados, além de autores que se apropriam dos conceitos fundamentais das profissões para caracterizar a profissionalização no campo da Educação como Goodson (2008), Tardif (2002), entre outros.

\footnotetext{
${ }^{3}$ Colégio Brasileiro de Ciências do Esporte.

${ }^{4}$ Conglomerado empresarial responsável pela gestão de diversas Instituições de Ensino Superior privadas.
} 
Entre os diferentes aspectos que serão abordados neste trabalho, entendemos o conceito de profissão como um método de controle do próprio trabalho (FREIDSON, 1998). O conceito de profissionalismo (ou profissionalidade), por sua vez, pode ser definido como um conjunto de atributos tidos como característico dos profissionais, envolvendo condutas, valores e responsabilidades reconhecidos socialmente (RODRIGUES, 2002; FREIDSON, 2009). Envolve ainda uma preocupação maior "com a acção intrincada da acção ocupacional e do seu carácter - neste caso, a prática e a profissão de ensinar" (GOODSON, 2008, p.2010). Finalmente, compreende-se por profissionalização um "processo que transforma uma atividade desenvolvida no mundo do trabalho mediante a circunscrição de um domínio de conhecimentos e competências específicas" (WEBER, 2003, p. 1127), bem como "a promoção de interesses materiais e ideias de um grupo ocupacional" (GOODSON, 2008, p. 2010).

De acordo com Bourdieu (1996, p. 50) "o campo é tanto um 'campo de forças', uma estrutura que constrange os agentes nele envolvidos, quanto um 'campo de lutas', em que os agentes atuam conforme suas posições relativas no campo de forças, conservando ou transformando a sua estrutura". Nesta lógica, o grau de conhecimento e a capacidade de aplicação de soluções para as questões que emergem na estrutura social são desenvolvidos por pessoas reconhecidas por terem o domínio de conhecimentos especializados, a partir de um treinamento específico, que os legitimam a intervir nos diversos setores que compõem a sociedade. Estes sujeitos são chamados de profissionais e compõem o que chamamos de "grupos profissionais".

O maior privilégio de fazer parte de um grupo profissional é ter acesso ao ensino profissional reconhecido publicamente, que habilite o profissional a assumir um status, legitimado frente à sociedade. $\mathrm{O}$ conhecimento exclusivo e o ensino especializado são prerrogativas para uma reserva de mercado como direito. Por este motivo, as profissões buscam a autorregulação por meio de alguns elementos estruturais, os quais são: um corpo sistemático de teorias, o exercício da autoridade profissional, sanção da comunidade para gerir o treinamento e a estrutura da própria profissão, são orientados por um código de ética e desenvolvem uma cultura profissional, respeitando valores, normas e símbolos vinculados às suas práticas sociais (ROSAS, 1975).

Esses elementos, que estruturam o campo profissional, sintetizam a forma como os membros das ocupações se articulam em prol de um empreendimento profissional. O projeto profissional pressupõe uma ideologia a ser seguida pelo grupo, a favor ou contrária ao desenvolvimento do seu profissionalismo.

O status atribuído às profissões nas sociedades modernas tem como consequência inegáveis privilégios, que todas as profissões almejam: reserva de mercado, investimentos na formação profissional e, acima de tudo, responsabilidades sociais (ABBOTT, 1988; COELHO, 2001).

Em face desses apontamentos, este estudo tem como objetivo identificar e analisar nas manifestações sobre a Minuta de Projeto de Resolução das DCNs/EF as tensões e conflitos no campo da Formação Profissional sob a perspectiva da Profissionalização da Educação Física na contemporaneidade.

\section{Metodologia}

Este estudo define-se como qualitativo, de caráter descritivo-interpretativo, pois visa mapear os posicionamentos, as concepções e ideologias em torno da formação profissional em Educação Física e suas bases epistemológicas, tendo como fonte de dados quatro eventos que foram gravados em vídeo/áudio pelas próprias instituições promotoras deles, sendo disponibilizados na rede online (internet) ao público em geral. 
Sobre a utilização de vídeos como material de análise em pesquisas, Lima (2015) aponta que é comum os pesquisadores assistirem aos vídeos e, logo depois, transcreverem as falas dos sujeitos envolvidos nas investigações, com o objetivo de utilizá-las em seus trabalhos. O uso do vídeo como ferramenta de pesquisa pode ser utilizado de várias maneiras: vídeo participativo, quando o próprio sujeito produz e analisa o material; videografia, quando a gravação é utilizada para estudo da cultura e da participação do sujeito no meio cultural; vídeo de elicitação, para o levantamento de opiniões e consulta a projetos, muito utilizado em grupos focais; trabalho de campo baseado em vídeo, utilizado principalmente em estudos interacionistas; e o uso de vídeos já existentes, chamados por JEWITT (2012) de vídeos com redefinição de objetivos, justamente porque são utilizados com um propósito diferente do original.

Partindo dessa caracterização, desenvolvemos o presente estudo com base em vídeos/áudios já existentes. Optamos por transcrever as falas dos participantes (caracterizados como informantes) de cada encontro ou audiência pública, em torno do debate sobre as DCNs/EF, gerando o total de 39 páginas para a análise, tendo como referência o quadro abaixo.

Quadro 1 - O debate sobre as novas reformulações das DCNs/EF

\begin{tabular}{|c|c|c|c|}
\hline Evento & $\begin{array}{l}\text { Data de } \\
\text { realiza- } \\
\text { ção }\end{array}$ & Local & Link do áudio/vídeo \\
\hline $\begin{array}{l}\text { Debate sobre a refor- } \\
\text { mulação } \\
\text { DCNs/EF }\end{array}$ & $10 / 10 / 2015$ & $\begin{array}{l}\text { PUC - Goiânia/ } \\
\text { Goiás }\end{array}$ & https://www.youtube.com/watch?v=p2qRuNWtjW0 \\
\hline $\begin{array}{l}\text { Audiência Pública } \\
\text { Educação Física }\end{array}$ & $11 / 12 / 2016$ & $\begin{array}{l}\text { CNE - Brasília/ } \\
\text { Distrito Federal }\end{array}$ & $\begin{array}{l}\text { http://centraldemidia.mec.gov.br/index.php?option=com_- } \\
\text { hwdmediashare\&view=mediaitem\&id=10812:audiencia- } \\
\text { publica-educacao-fisica-11-12-15?\&filter_mediaType=1 } \\
\text { (somente áudio) }\end{array}$ \\
\hline $\begin{array}{l}\text { Reunião } \text { Diretrizes } \\
\text { (exposições e plená- } \\
\text { ria) }\end{array}$ & $11 / 03 / 2016$ & $\begin{array}{l}\text { USP - São Pau- } \\
\text { lo/ São Paulo }\end{array}$ & $\begin{array}{l}\text { https://www.youtube.com/watch?v=pBYcz3YZLH8 } \\
\text { https://www.youtube.com/watch?v=X37xS0I0_9I }\end{array}$ \\
\hline $\begin{array}{l}\text { Mesa Diretrizes Cur- } \\
\text { riculares EF (parte } 1 \text {, } \\
2 \text { e 3) }\end{array}$ & $29 / 04 / 2016$ & $\begin{array}{l}\text { UFJF }- \text { Juiz de } \\
\text { Fora/ Minas } \\
\text { Gerais }\end{array}$ & $\begin{array}{l}\text { https://www.youtube.com/watch?v=OfZM1-8-JUg } \\
\text { https://www.youtube.com/watch?v=AieQ-wIEXmA } \\
\text { https://www.youtube.com/watch?v=whWra0uSTfI }\end{array}$ \\
\hline
\end{tabular}

Analisou-se, individualmente, as exposições, através das transcrições dos áudios dos discursos dos participantes. Apesar dos vídeos/áudios estarem à disposição do público em geral, optamos por codificar cada informante, de forma a preservar sua identidade e despersonalizar a construção do corpus de análise.

Seguindo as indicações de Lima (2015) todas as falas foram organizadas com o registro do tempo inicial e final de cada exposição para possibilitar a consulta ao vídeo/aúdio posteriormente. Chamamos esta fase de transcrição-descritiva. A próxima fase caracteriza-se pela leitura e seleção dos eventos críticos, chamada de interpretativa ou inferencial (POWELL; FRANCISCO; MAHER, 2004). Os eventos críticos são os momentos relevantes da fala dos informantes que nos remontam ao arcabouço teórico-metodológico assumido no trabalho. Neste momento os dados começaram a ser mapeados e procedeu-se à análise temática dos áudios transcritos.

A partir desta leitura emergiram quatro eixos de análise, que se referem aos posicionamentos com relação às perspectivas apresentadas pelas DCNs/EF: reformadores (que defendem uma formação única); defensores (que defendem a manutenção da formação atual); debatedores (defendem a especificidade da formação, propondo repensar a formação na área) e mediador (ocupa o papel de conduzir este debate em direção aos interesses do conjunto da 
sociedade). Cada grupo apresentou discursos, argumentos e proposições com valores, ideologias e representações de grupos diferenciados da sociedade.

\section{O campo profissional, como um espaço de lutas e disputas}

Bourdieu pontua que "às diferentes posições que os grupos ocupam no espaço social correspondem estilos de vida, sistemas de diferenciação que são a retradução simbólica de diferenças objetivamente inscritas nas condições de existência" (BOURDIEU, 1983, p. 82). Essas condições de existência se configuram em uma relação de força que muitas vezes são ofuscadas pela legitimidade. Sendo assim, quando olhamos os diferentes interlocutores dos debates em torno da formação profissional em Educação Física, motivados pelas novas diretrizes curriculares, devemos considerar os seguintes aspectos: (a) quais são os grupos, ou seja, de onde parte o olhar sobre a formação profissional em Educação Física?; (b); quais as motivações para cada posicionamento?; e, acima de tudo: (c) qual é a ideologia profissional que permeia as argumentações?

As análises das transcrições foram organizadas em quatro eixos: "Reformadores", "Defensores", "Debatedores" e "Mediador", os quais serão apresentados a seguir.

\section{(1) Reformadores}

O grupo denominado "reformadores" não se refere a um coletivo único em termos de concepções, visões políticas ou mesmo de agentes sociais. De fato, compõe esse grupo diferentes agentes, com destaque para membros do CNE, propositores institucionais da alteração curricular, alguns pesquisadores da área da Educação Física, representantes de instituições de ensino superior privadas, alguns coordenadores de cursos de graduação (tanto em instituições públicas quanto particulares) e, ainda, representantes de grupos de estudantes de graduação. Movidos por motivos e interesses diversos, todos esses agentes congregam falas que endossam a necessidade das alterações para as novas diretrizes curriculares, com especial atenção à concepção de ato educativo para toda e qualquer intervenção do profissional de EF e a importância de convergência das modalidades de licenciatura e bacharelado para uma única formação.

Nessa direção, os discursos apresentados pelo informante A (similar em todos os encontros assinalados), toma como referência o modelo oriundo dos cursos de pedagogia. Assim, para ele:

Os cursos de pedagogia tinham duas alternativas de formação: o bacharelado e a licenciatura. Essas duas alternativas atendiam mais ou menos a duas concepções. A licenciatura, para outros, devia atender às escolas, quer dizer, formar professores para as escolas, e o bacharelado devia formar gestores das escolas. E por outro lado, a outra concepção é a seguinte: nós não precisamos diferenciar esses dois mundos, podemos unificá-los e ter apenas uma formação e todos os pedagogos deverão ser licenciados e aí eles vão atender a todas as realidades escolares: a da docência e a da gestão (...) O curso de pedagogia passou a ser licenciatura e ponto. Não se fala em outra alternativa de formação (INFORMANTE A).

Em outro evento, o mesmo informante A salientou: "isso aconteceu na pedagogia e a proposta que nós estamos apresentando é similar aqui. É de compreender o ato de intervenção deste egresso como um ato educativo pela natureza (...) desta atividade e, portanto, prevê uma formação unificada em torno da licenciatura". Ao tomar como referência as diretrizes oriundas dos cursos de pedagogia, tem-se a pretensão de justificativa advinda do "ato educativo", 
isto é, de que toda e qualquer intervenção realizada por profissional de Educação Física, independente do contexto, é uma prática educativa, o que justificaria a tese de uma formação única.

Para a "reforma" do grupo profissional, é imprescindível um elemento aglutinador e promotor do sentimento de pertença. Na perspectiva das profissões, a orientação para um elemento único, norteador da identidade profissional no coletivo do grupo, é uma estratégia para atribuir legitimidade à proposta dos reformadores.

Ainda para o informante A:

Nós precisamos pensar a questão de fundo, que é: a que serve o profissional de Educação Física. E parece que há muitas compreensões, e eu estou desenvolvendo essa mesma compreensão: de que o ato profissional de um educador físico é sempre um ato educativo. Isso nos ajuda a seguir para um certo campo. A experiência da pedagogia também nos ajuda. Ora, embora houvesse algumas vozes discordantes bem duras quando o parecer da pedagogia foi aprovado, não houve nenhuma catástrofe, o mundo não acabou por conta disso, muito pelo contrário (INFORMANTE A).

É importante ressaltar que embora exista a construção de um novo "ideal” profissional para conquistar a aprovação do grupo profissional para uma nova orientação na formação e na intervenção, o cenário utilizado como referência está centrado no campo da pedagogia, o qual tem como objetivo o estudo dos processos de ensino, aprendizagem e gestão no campo educacional. Tal ponto de referência para as argumentações a favor da "reforma" na Educação Física pode ser uma estratégia abstrata para os sujeitos que não estão diretamente envolvidos em campos educacionais na Educação Física, como no esporte de alto rendimento e o campo do fitness, por exemplo. Como Dubar (2005) esclarece, é necessária uma interação das percepções internas (de si) e externas (atribuídas por outros) para a construção da identidade socialprofissional. É com a aceitação e a vivência do papel ocupacional que a identidade é incorporada.

Endossam a fala institucional (CNE) os informantes B, C e D. O informante C, por exemplo, ao analisar historicamente a criação dos cursos de bacharelado em Educação Física, remeteu a divisão das modalidades a uma possível fragmentação da formação. Para ele: "desde 1987 a única coisa concreta que temos com a divisão da formação é ela própria a fragmentação, cujo produto se materializa na emissão de certificados diferentes para uma formação muito próxima". O informante B apoia as proposições institucionais, reforçando o caráter educativo do profissional de EF, bem como o direito do trabalhador. Nesse intento, fica claro na fala do informante B certa oposição às delimitações apresentadas pela Lei 9696/98, que regulamenta a profissão de Educação Física, bem como salienta divergências para com os órgãos reguladores e fiscalizadores da profissão (sistema CREF/CONFEF):

O nosso país garante a todo o cidadão o direito ao trabalho e isso tem que ser garantido. Uma lei menor não pode inviabilizar o trabalho de quem se forma nas universidades [...]. Portanto, não pode nenhuma lei, nenhum organismo que limite a possibilidade de acesso a esse patrimônio (INFORMANTE B).

De forma curiosa, tem-se ainda o apoio de parte das instituições de ensino superior privadas. A partir da fala do informante $\mathrm{D}$, representante de mantenedoras particulares, tem-se que: "A proposta das Diretrizes está muito bom [sic]. O setor privado fica muito feliz de ter essa discussão e realmente ela está simples, mas está direta sem acarretar um grande engessamento nas instituições”. Esse posicionamento oferece margem para a discussão dos motivos 
que levam atores cujos posicionamentos e concepções políticas e teóricas historicamente tendem a diferir-se entre si, mas que nessa dinâmica posicionam-se como apoiadores mútuos. Bourdieu (1974) exemplifica tal fato a partir da caracterização de um possível "pacto de nãoagressão" entre agentes que não se encontram em situação de disputa direta, mesmo que possam divergir entre outras questões. Em tese, parte dos atores do grupo dos reformadores apresentam embasamentos diferentes - e até contraditórios - mas que defendem o mesmo posicionamento com relação às $\mathrm{DCNs} / \mathrm{EF}$, colocando-os no mesmo grupo.

Válido destacar, ainda, que para uma parcela dos reformadores parece estar em jogo motivações que extrapolam as questões afeitas à formação profissional, nomeadamente a defesa do livre acesso ao mercado de trabalho, vinculada ao reconhecimento da atuação plena do licenciado. No caso do CNE, a atuação plena do licenciado parece se configurar como uma questão de princípio, para não dizer de honra, frente aos desdobramentos da decisão em caráter terminativo (julgamento de recurso repetitivo) do Supremo Tributal de Justiça ${ }^{5}$ e da interferência do Sistema CREF/CONFEF na exigência de credenciamento dos licenciados atuantes na Educação Básica.

\section{(2) Defensores}

O grupo dos defensores foi caracterizado em sua maioria por representantes de entidades de classe, mas também por professores e pesquisadores da área da Educação Física, os quais defendem a manutenção dos cursos de licenciatura e bacharelado, com base na formação de um profissional capaz de oferecer um serviço especializado, o que exigiria um currículo com identidade própria, diferente dos currículos de licenciatura, que tem seu escopo de formação a atuação na Educação Básica.

[...] embora possa haver aspectos formativos comuns entre licenciatura e o bacharelado em Educação Física, cada um desses cursos são independentes em relação aos seus objetivos, perfis de egressos, matriz curricular, estágios e diplomas específicos, com ingressos independentes e terminalidade própria e, consequentemente, o exercício profissional para os seus egressos é diferente em sua essência (INFORMANTE Q).

Sendo assim, as concepções deste grupo giram em torno da especificidade demandada pelo campo de atuação e não pelos elementos que fazem parte da identidade coletiva da Educação Física. Os argumentos, neste caso, estão voltados para o distanciamento da noção coletiva sobre a intervenção e a construção de fundamentos em torno da necessidade de diferentes bases de conhecimentos para garantir a melhor intervenção em diferentes campos de atuação.

Para os informantes, é relevante ter a compreensão de que o curso de licenciatura em Educação Física deveria formar professores qualificados para atuar, exclusivamente, na Educação Básica. A formação do licenciado é específica para atuar na escola e deve estar amparada nos pressupostos emanados pela Resolução 02/2015 (BRASIL, 2015) que valoriza a formação para atuar nas instituições de ensino básico.

Eu penso exatamente o contrário do que se está discutindo, que a licenciatura é uma proteção ao ambiente escolar que nós devemos ter e o bacharelado é o meio de formação de pessoas que vão dar uma demanda extraescolar. [...] se a licenciatura não tiver amparo na $02 / 2015$ se preocupando com o ambiente escolar e produzindo uma demanda de disciplinas que vão proteger essa de-

\footnotetext{
5 A referida decisão pode ser encontrada no seguinte link do Superior Tribunal de Justiça: https://ww2.stj.jus.br/processo/revista/documento/mediado/?componente=ATC\&sequencial=41910237\&num_re gistro $=201300117283 \&$ data $=20141118 \&$ tipo $=5 \&$ formato $=P D F$
} 
manda escolar, daqui a pouco vamos ter um curso de bacharelado com o nome de licenciatura (INFORMANTE P).

A profissionalização de uma ocupação pressupõe o desenvolvimento de seu repertório de conhecimentos no decorrer de sua história. A ideia é que a ocupação parte de um exercício profissional menos complexo e se desenvolve, construindo novos conhecimentos, transformando sua prática em algo mais complexo e elaborado (FREIDSON, 1998). Sendo assim, as generalizações são perigosas para um entendimento mais aprofundado das ocupações e os argumentos dos "defensores" ressaltam a complexidade ocupacional da Educação Física.

Por esse motivo, outros defensores são enfáticos em combater a possibilidade de uma atuação "plena" para o licenciado em Educação Física:

[...] na nossa especificidade temos lutado incansavelmente para mudar o pensamento arcaico de que o licenciado pode tudo, modelo de formação predominante enquanto vigoraram as resoluções 69/69 e 03/87, que perdurou até 2002, recuperando o enfoque educacional, formativo e inclusivo, que deve orientar a prática docente do licenciado em Educação Física de modo a contribuir para a tão almejada qualidade da Educação Básica no Brasil (INFORMANTE Q).

Temos que ter o licenciado na escola e ele é a nossa base principal e nós não temos problema nenhum em registrar o bacharel ou o licenciado (INFORMANTE M).

De modo geral, os defensores postulam que houve no Brasil uma ampliação do mercado de trabalho para os egressos dos cursos de Educação Física. Tal ampliação foi gerada por uma demanda social por serviços, sobretudo, na área da saúde, mas também em outros campos fora do contexto escolar. Esse crescimento e diversificação do mercado de trabalho tem justificado a pertinência de uma formação, nesse caso do bacharel em Educação Física, que dialogue com as demandas sociais.

\section{(3) Debatedores}

Para os "debatedores", a Educação Física desde a década de 1980 tem construído seu repertório de conhecimentos específicos, denominado pelo Informante $\mathrm{X}$ de "conhecimento identificador da área". Ainda para ele: "Seja falar de objeto de ensino e pesquisa, seja falar da própria tradição, [...] nós sabemos fazer coisas né, nós sabemos ensinar esporte, nós sabemos ensinar a nadar, a fazer musculação, isso é da tradição da área" (INFORMANTE X). Nesse sentido, na perspectiva do informante $\mathrm{X}$, a existência de um núcleo identificador para a Educação Física é o elemento que fortaleceu o reconhecimento social do profissional e de sua intervenção em diferentes espaços, como na saúde, no lazer e no esporte.

Hoje nós temos um reconhecimento social, que tem um profissional que lida, que é da Educação Física. Muitas vezes chamadas de professor de Educação Física, que desde que professor é profissional compartilham a mesma origem etimológica que é 'prof' [sic], que quer dizer alguém que professa algo (INFORMANTE X).

Sendo assim, os "debatedores" argumentam também que o entendimento inicial que devemos ter sobre a formação é que

[...] todas as profissões que envolvem ações humanas e nas quais a aprendizagem com o contato com o cliente, com o aluno, com quem quer que seja, 
implica numa eficácia da intervenção lato sensu. Não quer dizer que o médico tem que fazer licenciatura[...] (INFORMANTE X).

$\mathrm{Na}$ visão do informante $\mathrm{X}$, há "um grande equívoco de se confundir a educação no sentido lato com a educação escolarizada". Isto porque, o conhecimento profissional pressupõe um conjunto de saberes formalizados para a atuação especializada, característica distintiva dos profissionais. Entretanto, a educação especializada faz parte de um escopo mais amplo, onde as questões sociais sempre estarão presentes na formação de forma mais genérica. Dessa forma, a formação profissional não está centrada em si mesma. O que orienta o trabalho profissional é a forma como o conhecimento específico é utilizado para resolver problemas no processo de intervenção. O trabalho profissional é constituído por tarefas desempenhadas por pessoas que adquiriram algum conhecimento especializado e receberam treinamento específico, que lhes asseguram certa autoridade no exercício da ação profissional (ABBOTT, 1988).

Seguindo esta linha, para os "debatedores" o bacharelado tem como objetivo formar profissionais generalistas com o domínio do conhecimento de uma área específica, enquanto a licenciatura "pressupõe [...] que a atuação na escola demande conhecimentos, competências, habilidades, sensibilidades diferentes daquelas exigidas pelo bacharel" (INFORMANTE Y).

Não há mais lugar para profissional eclético. O que se requer é um profissional especialista, formado sobre uma base de conhecimentos de salas de aulas. [...] extinção do bacharelado [...] implica a volta da formação de um profissional eclético, sem perfil claramente definido e isso implica regredir 30 anos (INFORMANTE Y).

Para os "debatedores" as contribuições em torno das mudanças curriculares estariam diretamente vinculadas à caracterização do perfil do bacharelado no mercado de trabalho e na densidade das discussões sobre a formação do licenciado. Portanto, se reconhece que os elementos que caracterizam uma profissão, bem como o conhecimento exclusivo associado ao ensino especializado, emergem como componentes distintivos de um profissional para um trabalhador comum (BOSI, 1996; ROSAS, 1975). Em função dessa compreensão os debatedores propõem que o CNE ofereça reais oportunidades aos membros da própria Educação Física de discutirem e aperfeiçoarem um novo modelo de formação.

\section{(4) Mediador}

O CNE esteve envolvido em todo o processo de debates sobre as mudanças nas diretrizes curriculares na Educação Física. Entretanto, a posição central de representante do Estado no debate é minimizada quando o Informante $Z$ afirma "Não vim aqui para dizer o que vamos fazer ou o que não vamos fazer. Quem vai fazer é a sociedade brasileira, certo? O Conselho Nacional de Educação tem a obrigação de conduzir este debate em direção aos interesses do conjunto da sociedade".

Segundo Weber (1991) a disposição de uma ou várias pessoas, de se submeter à imposição de uma ordem, pressupõe a crença na autoridade daqueles que impõem esta ordem. Por este motivo, é comum em documentos de regulações sociais como resoluções, ofícios e leis, qualificar a relação social que se estabelece por meio dos instrumentos oficiais. Dessa forma o sistema de apoderamento da sociedade é co-participativo (TURNER, 1989), e fica evidenciado na forma como o CNE conduziu a introdução da Minuta e as argumentações em torno do papel desempenhado perante a sociedade.

Para o próprio CNE existe uma disputa interna no campo da Educação Física, que "precisa ser direcionada para a evolução da sociedade, dos cursos e currículos de Educação Física" (INFORMANTE Z). Porém, o fio condutor das mudanças é a noção de currículo fle- 
xível, uma estratégia para amenizar a imposição de um modelo rígido de reordenamento curricular, o qual no passado denominou-se pejorativamente de "currículos mínimos". Tanto no contexto do bacharelado quanto na licenciatura, a proposta de um currículo "flexível" foi mencionada em diversos momentos nas falas do "mediador". Para o Informante Z: "a associação com as práticas reais, o trabalho em conjunto com os alunos, uma nova forma de incentivar o aprendizado, até com novas tecnologias, é parte integrante da nova formação curricular".

Apesar da indicação de um encaminhamento mais aberto às diferentes propostas de formação na Educação Física, o fio condutor do discurso, construído para justificar a iniciativa do CNE para as mudanças no currículo da Educação Física está centrado: (a) na gestão universitária; (b) no aluno, sujeito da formação e; (c) na relação com o mercado de trabalho. Para que esses elementos tenham convergência, entende-se que as instituições devem "desburocratizar a estrutura curricular, mas que faça, que cada instituição possa pôr a sua personalidade na gestão, por isso que é só uma diretriz, não é currículo mínimo" (INFORMANTE Z).

Para o próprio CNE existe uma disputa interna no campo da Educação Física, que "precisa ser direcionada para a evolução da sociedade, dos cursos e currículos de Educação Física". Dessa forma, percebe-se que a referência central para a discussão dos processos sobre a formação na Educação Física pelo CNE é a sociedade. A sociedade é um termo genérico e abstrato, utilizado como refúgio aos enfrentamentos dos diversos grupos em disputa pela legitimidade de suas propostas.

Assim, o debate em torno do currículo e da formação profisssional em Educação Física é o meio pelo qual a ocupação exerce seu profissionalismo. Para Evetts (2003) o profissionalismo é um instrumento de troca e de controle ocupacional do mundo moderno e é construído e controlado por diferentes grupos. A autora propõe que a análise do profissionalismo também seja entendida como um valor normativo, um discurso sobre as trocas ocupacionais e do controle social, não diferente do que evidenciamos neste trabalho.

\section{Considerações finais}

As tensões, conflitos e disputas em torno das DCNs/EF trouxe à tona um embate entre grupos em confronto, interesses corporativos, parcerias entre polos opostos e a presença do Estado na figura do CNE.

O Encontro de Goiânia marcou o ponto de partida do que poderia vir pela frente sobre as DCNs/EF na forma de um "boato", no qual foram anunciadas as possibilidades de mudanças. Porém, cabe lembrar que o portador de um boato não o enuncia em qualquer lugar, nem diante de qualquer pessoa, mas apenas quando se sente estar entre cúmplices é que se dispõe a desvelar suas informações (OLIVEIRA, 2015). De modo que recorrer "a uma forma impessoal e anônima de apresentar uma informação pode ser tanto uma estratégia deliberada de atacar um rival evitando o embate direto, como uma forma espontânea de confrontar e avaliar as informações disponíveis" (OLIVEIRA, 2015, p.115). Porém, esta questão também nos lembra que "na maioria dos problemas humanos, não se parte dos fins nem dos meios, mas se começa pela metade, ou seja, pela confusão" (ANDRE, 1976, p. 3).

Assim, cada grupo analisado construiu um repertório de elementos que evidencia seu ponto de vista, ou seja, o ponto de partida sobre o qual argumentam. Os denominados de "Reformadores", grosso modo, partem da prática educativa como elemento identificador da área, a qual, por sua vez, justifica a formação profissional unificada. Os "Defensores" usam como base de referência para a argumentação a diversidade dos campos de atuação e a necessidade de distinguir a prática profissional em cada segmento (licenciatura e bacharelado). Os "Debatedores" argumentam que é preciso considerar que a base de conhecimentos deve orientar as discussões sobre um novo modelo de formação profissional, orientado para resolver proble- 
mas profissionais, mantendo-se, ao menos por hora, a distinção entre os cursos. E por fim, o "Mediador" tem como pressuposto que o principal objetivo da Educação Física é atender a sociedade e, portanto, a formação profissional deve ser pensada como uma forma de prestação de serviço à sociedade.

O panorama do debate em torno das novas diretrizes para a formação profissional na Educação Física evidencia a disputa de diferentes grupos por legitimidade coletiva, que por sua vez, irá impactar diretamente na identidade profissional da Educação Física no futuro.

Conclui-se que o campo profissional da Educação Física, a partir das análises empreendidas, se apresentou como um "campo de forças" e um "campo de disputas" em que os agentes atuam conforme suas posições relativas nesse espaço social, conservando, mudando ou transformando a sua estrutura, buscando consolidar certa hegemonia. No entanto, chama a atenção, quer seja na perspectiva das reformas ou do direito do trabalhador, quer seja na das propostas em vigor e não da sua transformação, a confluência em torno do livre mercado como elemento regulador das ações profissionais nesse campo. Portanto, se pergunta, na direção em que as reflexões estão sendo postas: "vale tudo"?

\title{
CONFLICTS AND TENSIONS IN PHYSICAL EDUCATION CURRICULUM GUIDELINES: THE PROFESSIONAL FIELD AS A SPACE OF STRUGGLE AND DISPUTES
}

\begin{abstract}
This study aimed to identify and analyze in the manifestations about DCNs/EF the tensions and conflicts present in Professionalization of Physical Education. We chose the descriptiveinterpretive approach, through video recording technique, with the selection of 9 informants. From data analysis emerged four strands, that refer to positions in relation to DCNs/EF: reformers; defenders; debaters; mediator. We concluded that in the discussion about PE guidelines it is hidden a perspective about professional field, bringing out clash of different groups, but also corporate interests, as well as the professionalization processes in dispute. In this way, the issue of free labor market put together historical antagonists, ignoring teacher education specificity.

Keywords: Physical Education. Curriculum. Professional Practice. Professional Review Organizations.

\section{CONFLICTOS Y TENSIONES EN LAS DIRECTRICES CURRICULARES DE LA EDUCACIÓN FÍSICA: EL CAMPO PROFESIONAL COMO ESPACIO DE PELEAS Y DISPUTAS}

\begin{abstract}
Resumen
Este estudio tuvo como objetivo identificar y analizar, en las manifestaciones sobre las $\mathrm{DCNs} / \mathrm{EF}$, las tensiones y los conflictos presentes en la profesionalización de la Educación Física. Elegimos el enfoque descriptivo-interpretativo, a partir de la técnica de grabación de vídeo, con la selección de 9 informantes. El análisis de datos se diseñó cuatro ejes, que se refieren a las posiciones con respecto a la DCNs/EF: reformadores; defensores; discutidores; mediador. Llegamos a conclusión de que en la discusión acerca de las directrices se oculta una perspectiva sobre el campo profesional, llevando a cabo choque de diferentes grupos, sino también los intereses corporativos, así como los procesos de profesionalización en disputa. En este proceso, la cuestión de mercado libre de trabajo une antagonistas históricos, ignorando la especificidad de la formación de maestros.
\end{abstract}


Palabras clave: Educación Física. Curriculum. Práctica Profesional. Organizaciones de Normalización Profesional.

\section{Referências}

ABBOTT, A. The System of Professions. Chicago: University of Chicago Press, 1988.

ANDRE, J. Papel del profesor de educación física y deportiva en el mundo moderno. STADIUM, Buenos Aires, v.10, n· 57, p. 3-7, 1976.

BOSI, M.L.M. Profissionalização e conhecimento: a nutrição em questão. São Paulo: Hucitec, 1996.

BOURDIEU, P. Esboço de uma teoria de prática. In: ORTIZ, R. Pierre Bourdieu. São Paulo: Ática, 1983.

O poder simbólico. Lisboa: Difel, 1989.

. Coisas ditas. São Paulo: Brasiliense, 1990.

Razões práticas: sobre a teoria da ação. São Paulo, Papirus, 1996.

BRASIL. Congresso Nacional de Educação. Resolução CNE/CES 7/2004, de 31 de março de 2004. 2015.

Congresso Nacional de Educação. Resolução CNE/CP 2/2015, de 2 de julho de

COELHO, E. C. As profissões imperiais: medicina, engenharia e advocacia no Rio de Janeiro, 1822-1930, Rio de Janeiro: Record, 1999.

DUBAR, Claude. A socialização: construção das identidades sociais e profissionais. São Paulo: Martins Fontes, 2005.

EVETTS, Julia - Sociología de los grupos professionales: historia, conceptos y teorias. In: Martinez, M., Carrreras, J. e Svensson, L. Sociologia de lãs Profesiones: pasado, presente y futuro. Murcia: DM Editora, 2003. p. 29-49.

FREIDSON, E. Renascimento do profissionalismo. São Paulo: Edusp, 1998.

FREIDSON, E. Profissão médica. São Paulo: Unesp: Porto Alegre, RS: Sindicato dos Médi$\cos , 2009$.

GOODSON, I. F. Conhecimento e Vida Profissional: estudos sobre educação e mudança. Porto: Porto Editora, 2008.

JEWITT, C. An Introduction to Using Video for Research. NCRM Working Paper Series, Report, London-UK, 2012. Disponível em < http://eprints.ncrm.ac.uk/2259/>. Acesso em 08 de julho de 2016. 
LIMA, F. H. Um método de transcrições e análise de vídeos: a evolução de uma estratégia. In: VII Encontro Mineiro de Educação Matemática (VII EMEM), 2015, São João Del Rei. Anais... São João Del Rei: Universidade Federal de São João Del Rei, 2015. v. 7. p. 1-11.

OLIVEIRA, J. C. M. Do boato à lenda. Comunicação informal e fronteiras identitárias nas origens da controvérsia donatista. Antiteses, v.8, n.16, p.111-129, jul./dez. 2015.

POWELL, A.; FRANCISCO, J.; MAHER, C. Uma abordagem à Análise de Dados de Vídeo para investigar o desenvolvimento de ideias e raciocínios matemáticos de estudantes. Tradução de Antônio Olimpio Junior. Boletim de Educação Matemática. Rio Claro: BOLEMA, n. 21, 2004;

RODRIGUES, M. L. Sociologia das profissões. 2. ed. Oeiras: Celta, 2002.

ROSAS, Paulo, Vocação e profissão. 3 ed. Editora Vozes. Petrópolis, RJ. 1975.

TARDIF, M. Saberes profissionais dos professores e conhecimentos universitários. Revista Brasileira de Educação. Rio de Jeneiro. Jan/Fev/Mar/Abr, n.13. p.5-24 2000.

TURNER, B. Status. Lisboa: Editora Estampa, 1989.

WEBER, M. Economia e Sociedade: fundamentos da socilogia compreensiva. Brasília, DF: Editora Universidade de Brasília, 1991.

WEBER, S. Profissionalização docente e políticas públicas no Brasil. Educação e Sociedade, v. 24, n. 85, p. 1125-1154, dez. 2003.

Recebido em: 10/07/2016

Revisado em: 10/10/2016

Aprovado em: 10/10/2016

Endereço para correspondência:

samuelsn@rc.unesp.br

Samuel de Souza Neto

Universidade Estadual Paulista "Júlio de Mesquita Filho"

Avenida 24 A, 1515

13506-900 Rio Claro - SP 